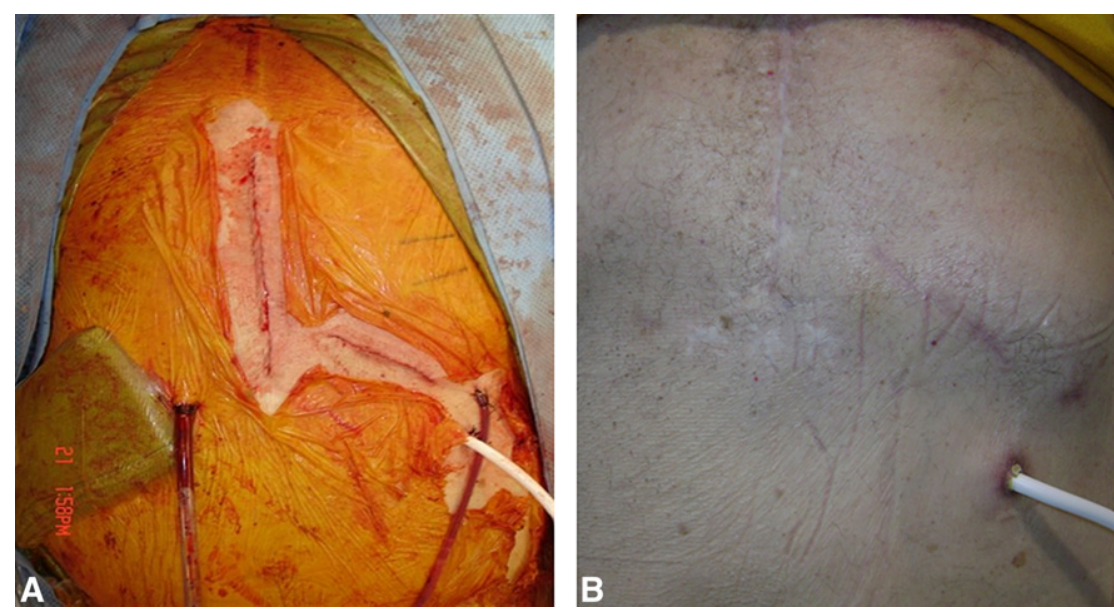

FIGURE 3. Surgical incisions after skin approximation (A) and 6 months after surgery (B).

previously ${ }^{2}$; however, the addition of balloon occlusion of the outflow graft allowed controlled exchange of the device without the need to surgically control and clamp the graft, ${ }^{3}$ reducing surgical dissection and potential morbidity. Placement of a Foley catheter into the outflow graft ${ }^{4}$ offers another option of controlling back bleeding from the aorta; however, connecting the outflow graft to the new device can be made difficult by uncontrolled bleeding because the Foley catheter must be removed. Furthermore, deairing of the outflow graft is more difficult with this approach, whereas endovascular control facilitates this process. We advocate a combined hybrid approach to device exchange in patients for whom minimal surgical trauma is paramount.

\section{References}

1. Kirklin JK, Naftel DC, Kormos RL, Stevenson LW, Pagani FD, Miller MA, et al. Fourth INTERMACS Annual Report: 4000 implants and counting. J Heart Lung Transplant. 2012;31:117-26.

2. Gregoric ID. Exchange techniques for implantable ventricular assist devices. ASAIO J. 2008;54:14-9.

3. Woo YJ, Acker MA. Implantable ventricular assist device exchange with focused intravascular deairing techniques. Ann Thorac Surg. 2011;91:306-7.

4. Rogers JG, Jollis JG, Milano CA. Replacement of continuous-flow left ventricular assist device via left subcostal incision. J Thorac Cardiovasc Surg. 2012;143:975-6.

\title{
Surgical treatment for secondary pneumothorax in patients aged more than 80 years
}

\author{
Hisayuki Shigematsu, MD, Akio Andou, MD, and Ryohei Higashi, MD, Okayama, Japan
}

Secondary pneumothorax in elderly patients is usually a refractory condition and sometimes leads to a fatal outcome because of underlying diffuse lung disease, such as emphysema and interstitial pneumonia. Surgical approaches should be considered for these patients after failure of chest drainage or pleurodesis; however, surgeons hesitate to apply surgical

\footnotetext{
From the Department of Chest Surgery, NHO Okayama Medical Center, Okayama, Japan.

Disclosures: Authors have nothing to disclose with regard to commercial support.

Received for publication Aug 17, 2012; revisions received Sept 18, 2012; accepted for publication Oct 2, 2012; available ahead of print Nov 22, 2012.

Address for reprints: Hisayuki Shigematsu, MD, Department of Chest Surgery, NHO Okayama Medical Center, 1711-1 Tamasu, Kita-ku, Okayama 701-1192, Japan (E-mail: ash-shige@ hotmail.co.jp).

J Thorac Cardiovasc Surg 2013;145:880-2

$0022-5223 / \$ 36.00$

Copyright (c) 2013 by The American Association for Thoracic Surgery

http://dx.doi.org/10.1016/j.jtcvs.2012.10.008
}

treatment because of concerns related to operative mortality and morbidity. We describe 11 patients aged more than 80 years with secondary pneumothorax who were successfully treated with surgical approaches.

\section{CLINICAL SUMMARY}

A total of 171 patients with primary or secondary spontaneous pneumothorax underwent surgical treatment at the NHO Okayama Medical Center between January 2005 and March 2012. Eleven patients $(6 \%)$ were aged more than 80 years with secondary pneumothorax. Table 1 summarizes the clinical features of these patients. All patients were male, and the median age at the time of surgery was 81 years (range, $80-95$ years). Ten patients had severe emphysema, 2 of whom were also diagnosed with interstitial pneumonia. Two patients were receiving home oxygen 
TABLE 1. Summary of preoperative and postoperative status in patients aged more than 80 years with secondary pneumothorax

\begin{tabular}{|c|c|c|c|c|c|c|c|c|c|c|c|c|}
\hline Case & Sex & Age (y) & Side & $\begin{array}{r}\text { Underlying } \\
\text { lung disease }\end{array}$ & Comorbid disease & PS & $\begin{array}{c}\text { Charlson } \\
\text { score }\end{array}$ & $\begin{array}{c}\text { Drainage } \\
\text { (d) before } \\
\text { surgery }\end{array}$ & Anesthesia & $\begin{array}{r}\text { Operation } \\
\text { time (min) } \\
\end{array}$ & Procedure & $\begin{array}{l}\text { Drainage } \\
\text { (d) after } \\
\text { surgery }\end{array}$ \\
\hline 1 & M & 88 & $\mathrm{R}$ & Emphysema & Bleeding peptic ulcer & 1 & 2 & 18 & $\mathrm{G}$ & 200 & $\begin{array}{l}\text { Bullectomy + PGA } \\
\text { sheet }+ \text { fibrin glue }\end{array}$ & 2 \\
\hline 2 & M & 82 & $\mathrm{R}$ & Emphysema & & 0 & 1 & 4 & $\mathrm{G}$ & 78 & $\begin{array}{l}\text { Bullectomy + PGA } \\
\text { sheet }+ \text { fibrin glue }\end{array}$ & 3 \\
\hline 3 & M & 80 & $\mathrm{~L}$ & Emphysema & & 1 & 1 & 10 & $\mathrm{E}+\mathrm{L}$ & 68 & PGA sheet + fibrin glue & 3 \\
\hline 4 & M & 80 & $\mathrm{~L}$ & Emphysema & HOT post-RLL & 2 & 3 & 22 & $\mathrm{E}+\mathrm{L}$ & 80 & PGA sheet + fibrin glue & 6 \\
\hline 5 & M & 81 & $\mathrm{R}$ & $\begin{array}{l}\text { Emphysema, } \\
\text { lung cancer }\end{array}$ & & 1 & 3 & 17 & $\mathrm{G}$ & 70 & PGA sheet + fibrin glue & 7 \\
\hline 6 & M & 88 & $\mathrm{R}$ & Emphysema & & 1 & 1 & 8 & $\mathrm{G}$ & 61 & $\begin{array}{l}\text { Bullectomy + PGA } \\
\text { sheet }+ \text { fibrin glue }\end{array}$ & 1 \\
\hline 7 & M & 80 & $\mathrm{R}$ & Pneumoconiosis & & 0 & 1 & 28 & $\mathrm{G}$ & 130 & $\begin{array}{l}\text { Bullectomy + PGA } \\
\text { sheet }+ \text { fibrin glue }\end{array}$ & 2 \\
\hline 8 & M & 81 & $\mathrm{R}$ & Emphysema, IP & & 1 & 1 & 17 & $\mathrm{G}$ & 81 & PGA sheet + fibrin glue & 1 \\
\hline 9 & M & 95 & $\mathrm{R}$ & Emphysema & Heart failure, dementia & 3 & 5 & 26 & $\mathrm{G}$ & 65 & $\begin{array}{l}\text { Bullectomy + PGA } \\
\text { sheet }+ \text { fibrin glue }\end{array}$ & 1 \\
\hline 10 & M & 81 & $\mathrm{~L}$ & Emphysema & Brain infarction & 1 & 4 & 8 & $\mathrm{G}$ & 71 & $\begin{array}{l}\text { Bullectomy + PGA } \\
\text { sheet }+ \text { fibrin glue }\end{array}$ & 2 \\
\hline 11 & M & 84 & $\mathrm{~L}$ & Emphysema, IP & HOT & 2 & 1 & 27 & G & 100 & $\begin{array}{l}\text { Bullectomy + PGA } \\
\text { sheet }+ \text { fibrin glue }\end{array}$ & 2 \\
\hline
\end{tabular}

$M$, Male; $R$, right; $L$, left; $I P$, interstitial pneumonia; HOT, home oxygen therapy; $R L L$, right lower lobectomy; $P S$, performance status; $G$, general; $E$, epidural; $L$, local; $P G A$, polyglycolic acid.

therapy. One patient had advanced lung adenocarcinoma. Three patients had poor performance status of $2 / 3$ on the criteria of the Eastern Cooperative Oncology Group scale, and 4 patients scored 3 or more on the Charlson score. All patients were managed with chest drainage before surgery because of persistent air leakage. Chemical pleurodesis was performed before surgery in 7 of 11 patients, but all procedures failed. The median duration of chest drainage until surgery was 17 days (range, 4-28 days). All patients underwent video-assisted thoracoscopic surgery (VATS) with 3 ports, and no cases were converted to thoracotomy. All patients under general anesthesia were extubated immediately in the operating room. Pain was well controlled, and there was no hemodynamic or respiratory instability in 2 patients under local and epidural anesthesia. The median operative time was 78 minutes (range, 61-200 minutes). We performed a minimal repair technique that targeted the active leakage point only. The leakage site was simply covered with absorbable polyglycolic acid (PGA) sheet and aerosolized fibrin glue in 4 patients. In 7 patients, an endostapler was applied at the leakage site, which was reinforced with PGA sheet and fibrin glue (Figure 1). The median duration of postoperative drainage was 2 days (range, 1-7 days). The postoperative courses were uneventful in all but 1 patient (case 8) who had pneumothorax on postoperative day 4. The chest tube was reinserted, and pneumothorax was cured by chemical pleurodesis on postoperative day 20 . One patient (case 5) died of lung cancer 8 months after surgery without recurrence of pneumothorax. The other patients had no recurrence during the follow-up period.

\section{DISCUSSION}

As life expectancy has increased, the number of elderly patients with diffuse lung disease, especially those aged more than 80 years, who require major surgery has increased. Because of the surgical risk in this population, clinicians tend to avoid surgery or apply less-invasive surgical procedures on the basis of age and comorbidity. However, advances in perioperative care and in surgical and anesthetic techniques have offered surgical therapy for elderly patients with comorbidities and contributed to the favorable results. Several reports on lung cancer surgery in octogenarians have been published that show its feasibility and acceptable outcomes. ${ }^{1}$ With careful perioperative management, age alone should not disqualify a patient for surgery.

Reports of the surgical results for pneumothorax in elderly patients have been limited, ${ }^{2}$ and there is no report focusing on octogenarians or the older population. Careful attention is needed when considering the treatment strategy for secondary pneumothorax in elderly patients compared with primary spontaneous pneumothorax in younger patients, who are relatively manageable because of the absence of underlying lung disease. ${ }^{3}$ Refractory pneumothorax requiring a longer period of chest drainage may result in deterioration of quality of life and induces other medical maladies, especially in elderly patients. After failure of chemical pleurodesis, minimally invasive surgery such as VATS should be applied to these patients to resolve persistent air leakage. "A puncture repair" that applies a patch over the hole using PGA sheets and fibrin glue is a simple and effective procedure to seal pulmonary air leakage. Furthermore, we and others ${ }^{4,5}$ have reported the 

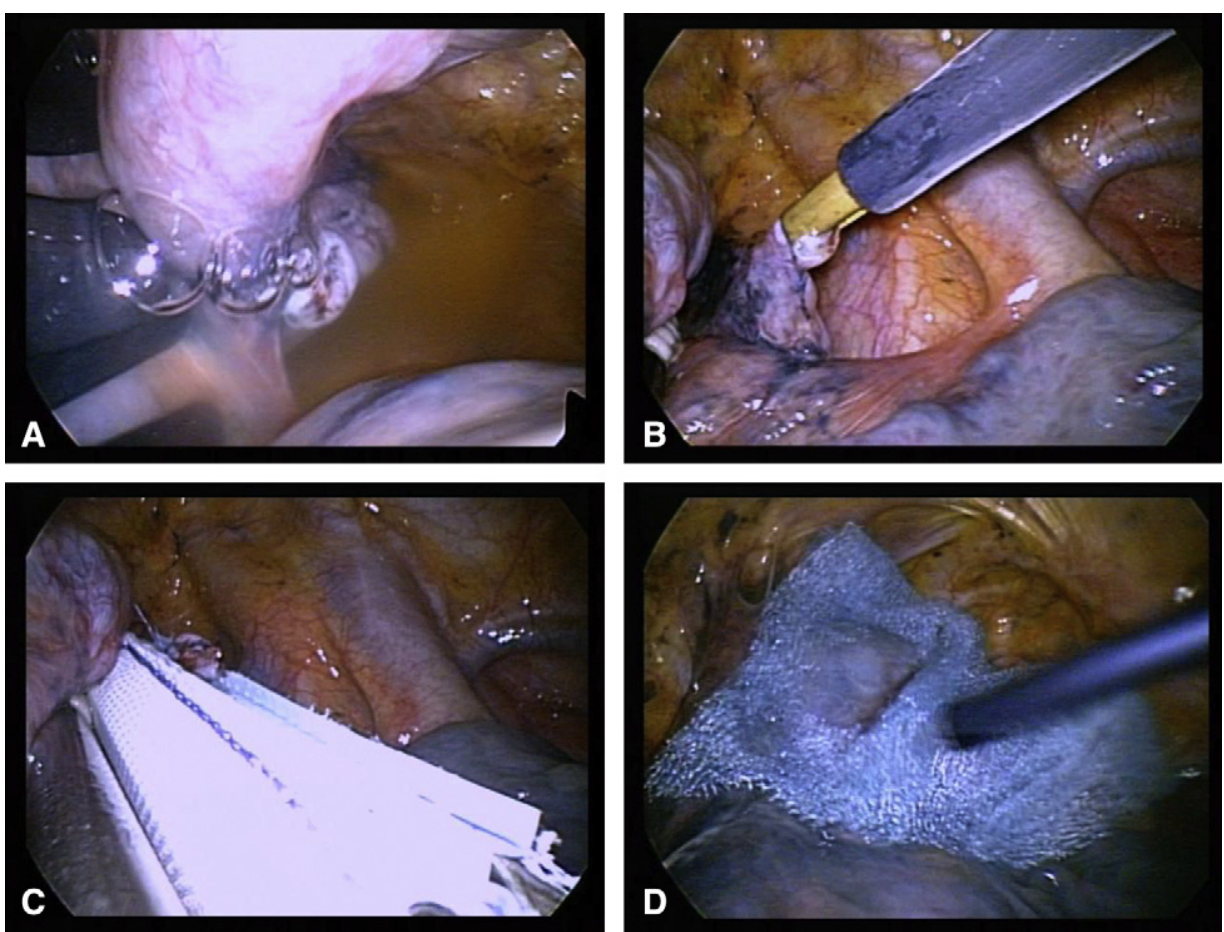

FIGURE 1. Representative repair technique (case 9). A, Specific site of air leakage was identified by lung inflation followed by underwater submersion. B and C, Bulla was resected with an endoscopic linear stapler. D, Lung surface around the suture line was covered with a PGA sheet and fibrin glue.

efficacy of VATS under local and epidural anesthesia to avoid adverse effects with single lung ventilation for intractable pneumothorax in high-risk patients. Despite including patients with a poor clinical condition, these surgical procedures were well tolerated in our series and allowed early resolution of pneumothorax without complications.

\section{CONCLUSIONS}

The minimally invasive surgical approach is an effective option even in elderly patients with intractable secondary pneumothorax.

\section{References}

1. Dillman RO, Zusman DR, McClure SE. Surgical resection and long-term survival for octogenarians who undergo surgery for non-small-cell lung cancer. Clin Lung Cancer. 2009; 10:130-4.

2. Onuki T, Murasugi M, Ikeda K, Oyama K, Nitta S. Thoracoscopic surgery for pneumothorax in older patients. Surg Endosc. 2002;16:355-7.

3. Heffner JE, Huggins JT. Management of secondary spontaneous pneumothorax. Chest. 2004;125:1190-2.

4. Mukaida T, Andou A, Date H, Aoe M, Shimizu N. Thoracoscopic operation for secondary pneumothorax under local and epidural anesthesia in high-risk patients. Ann Thorac Surg. 1998;65:924-6.

5. Shigematsu H, Andou A, Matsuo K, Satoh T, Higashi R. Thoracoscopic surgery using local and epidural anesthesia for intractable pneumothorax after BMT. Bone Marrow Transplant. 2011;46:472-3.

\title{
A simple technique of commissural reconstruction in aortic valve-sparing surgery
}

\author{
Hunaid A. Vohra, MD, MRCS, FRCS (CTh), FETCS, Laurent deKerchove, MD, \\ Jean Rubay, MD, PhD, and Gebrine ElKhoury, MD, Brussels, Belgium
}

\footnotetext{
From the Divisions of Cardiothoracic and Vascular Surgery, Université Catholique de Louvain, Cliniques Universitaires Saint-Luc, Brussels, Belgium.

Disclosures: Authors have nothing to disclose with regard to commercial support.

Received for publication April 28, 2012; revisions received Oct 4, 2012; accepted for publication Nov 6, 2012; available ahead of print Dec 10, 2012.

Address for reprints: Gebrine ElKhoury, MD, Service de Chirurgie Cardiovasculaire et Thoracique, Cliniques Universitaires Saint-Luc UCL, Ave Hippocrate 10, Brussels B-1200, Belgium (E-mail: gebrine.elkhoury@uclouvain.be).

J Thorac Cardiovasc Surg 2013;145:882-6

$0022-5223 / \$ 36.00$

Copyright (c) 2013 by The American Association for Thoracic Surgery http://dx.doi.org/10.1016/j.jtcvs.2012.11.021
}

Techniques of aortic valve repair have proven efficacy; however, these techniques cannot be used to treat all types of valves. In several instances, valve morphology requires commissural reconstruction (CR) with variable cusp extension. Generally, cusp extension techniques are performed with 2 or 3 distinct pericardial patches, which are joined on the aortic root wall to create the neocommissures. ${ }^{1,2}$ We have developed a method of CR with a single pericardial patch, as adapted from a technique described by Tolan and colleagues ${ }^{3}$ in 1997. 